Revista Multidisciplinar do Nordeste Mineiro, v.1,

$2021 / 01$

ISSN 2178-6925

\title{
CONSIDERAÇÕES DA CULTURA E DA SOCIEDADE NA EDUCAÇÃO
}

CONSIDERATIONS OF CULTURE AND SOCIETY IN EDUCATION

José Marciel Araújo Porcino

Bacharelado em Psicologia Pelo Centro Universitário de Patos-UNIFIP, e Licenciando

Pedagogia pela Universidade Federal da Paraíba-UFPB na modalidade de Educação a Distância-EAD , Brasil.

E-mail: leicram ap@hotmail.com Francisco Sales de Sousa Filho Pós Graduando em Geografia, Licenciado em História, Brasil.

E-mail: Francisco.filho6@professor.pb.gov.br

Valéria Amanda Jerônimo Pereira Pinto

Graduada em Psicologia Pela Universidade Federal da Paraíba-UFPB, pós graduanda em Neuropsicologia Pelo Centro Universitário de João Pessoa- UNIPÊ. E-mail: valeriaamanda@hotmail.com Silmaria Bezerra Porcino

Mestre em Ciências da Educação Pelo Instituto Superior de Educação Professora Lúcia Dantas-ISEL e Graduada em Serviço Social Pela Universidade Federal da ParaíbaUFPB, Brasil.

E-mail: siwmarya@hotmail.com João Erikes Almeida Marques

Licenciando em Ciências Biológicas pela Universidade Federal da Paraíba-UFPB na modalidade de Educação a Distância-EAD, 


\title{
Resumo
}

O presente trabalho objetiva considerar a cultura e a sociedade na educação. Nessa ação de conhecimento, entende-se que a cultura é compreendida como um movimento histórico e social que diáloga com todos os segmentos da sociedade. Foi utilizada a revisão de literatura. embasa-se em autores como Machado (2002), Moreira e Candau (2012), e Giddens (2005). E para interliga a metodologia proposta nessa pesquisa, também se fez do uso do materialismo do discurso analítico, critico e reflexivo a luz do pensamento da cultura e educação. A cultura é a identidade de um povo que vive em determinada localização, onde seus atores sociais: escola-gestãoaluno-família assumem múltiplos papéis sociais; atribuindo-se responsabilidade, competência, habilidades artísticas, habilidades profissionais e valores culturais. Que muitas vezes, alguns não são aceitos pela sociedade de maneira geral, mas, que assumem papéis correspondentes as normas e costumes construído ao longo da história da humanidade. Percebe-se que a socialização está ancorada nas relações sociais e suas configurações de construção de laços afetivos e emocionais que se estabelecem na infância com as pessoas de referencias nos vínculos familiares. Ou seja, ocorre o compartilhamento voluntário e involuntário de comportamentos, gestos, linguagem, brincadeira, valores, costumes, crenças e atitudes, os quais a criança, tende-se a introjetar e/ ou projetar no presente futuro, de modo que servirá de base para replicar ou não na segunda fase. Compreendemos que o campo pedagógico são provocações e as condições às quais a pessoa/ ou aluno tende-se a atuar de forma autônoma, onde sua capacidade reflexiva e critica da realidade o transportará para a criação do seu mundo, de forma responsável e coerente com o mundo, com as pessoas e principalmente consigo mesmo. Assim, dando ênfase a reflexão-açãorealidade diante de si e do outro significante diante de uma cultura e sociedade educada.

Palavras-chave: Gestão; ensino; organização; aprendizagem.

\begin{abstract}
The present work aims to consider culture and society in education. In this action of knowledge, it is understood that culture is understood as a historical and social movement that dialogues with all segments of society. literature review was used. it is based on authors such as Machado (2002), Moreira and Candau (2012), and Giddens (2005). And to link the methodology proposed in this research, the materialism of analytical, critical and reflective discourse was also used in the light of the thought of culture and education. Culture is the identity of a people who live in a specific location, where their social actors: school-management-student-family assume multiple social roles; assigning responsibility, competence, artistic skills, professional skills and cultural values. That many times, some are not accepted by society in general, but, that assume roles corresponding to the norms and customs built throughout the history of humanity. It is noticed that socialization is anchored in social relations and their configurations of building affective and emotional bonds that are established in childhood with people of reference in family bonds. In other words, there is a voluntary and involuntary sharing of behaviors, gestures, language, play, values, customs, beliefs and attitudes, which the child tends to introject and / or project into the present future, so that it will serve as a basis to replicate or not in the second phase. We understand that the pedagogical field are provocations and the conditions to which the
\end{abstract}


person / student tends to act autonomously, where his reflexive and critical capacity of reality will transport him to the creation of his world, in a responsible and coherent way. world, with people and especially with yourself. Thus, giving emphasis to reflectionaction-reality before you and the significant other before an educated culture and society.

Keywords: Management; teaching; organization; learning.

\section{Introdução}

O presente trabalho objetiva considerar a cultura e a sociedade na educação. Nessa ação de conhecimento, entende-se que a cultura é compreendida como um movimento histórico e social que diáloga com todos os segmentos da sociedade. $E$ por sua vez, a sociedade é vista como a organização sistemática e dinâmica de um povo, país e/ou continente que traduzem e evidenciam suas tradições, crenças, costumes, hábitos e estilos de vida.

Nessa conjuntura, múltiplos empecilhos de ordem cultural e social, muitas vezes, podem provocar divergências entre os povos inseridos em um dado contexto situacional e relacional. E para manter harmonia diante dos aspectos da cultura e da sociedade; a educação surge como elemento emancipador que integra harmoniosamente: o respeito, a tolerância, empatia, aceitação e a consciência crítica e reflexiva em face aos parâmetros organizacionais da vida em sociedade.

No que tece ao campo do território da área social, observa-se que a cultura caminha de mãos dadas com a sociedade em prol do bem comum; que é o desenvolvimento da comunidade. Assim, tanto a cultura como a sociedade, transmitem elementos que dão subsídios para sustentabilidade da moral, da ética, da transparência, das normas e regras de convivência numa sociedade.

E para esse objetivo presente, a educação é vista como pilar primordial que considera a importância do conhecimento e do saber da cultura e da sociedade no processo de ensino e aprendizagem. Uma vez que a educação nasceu como norma educacional da própria conjuntura da cultura e da sociedade.

De outra forma, as configurações da educação nos dias atuais, situam-se em diálogo interativo na construção da realidade entre a cultura e a sociedade (MARTINS; 2016), isso implica considerar a cultura e a sociedade como elo motriz da construção dessa realidade, onde todos possam partilhar da educação como um processo contínuo.

No plano institucional, a cultura dita o ritmo da organização. Logo, assim, a escola é uma instituição de ensino e aprendizagem que faz parte de uma sociedade que em tese é vista como função social e cultural da própria educação. Além disso, considerar esses aspectos significa que cada um desses fundamentos está associado a um único contexto que é da pessoa de um individual a um coletivo e 
vice-versa ( Machado, 2002), por essas razões, o artigo objetiva considerar a importância da cultura e da sociedade na educação do ser humano.

De outra forma, o presente trabalho é relevante para área educacional, e sua interface com o campo antropológico, histórico, pedagógico, psicológico e sociológico, pois, implicam nas considerações desses saberes. Por isso, esse artigo vislumbra a tecer nessa área, de modo geral a considerar a importância da cultura na educação.

Para atender os anseios dessa problemática em questão, foi utilizada a revisão de literatura. Sampieri, Collado e Lucio (2013, p.76) enfatizam que o ponto de vista da revisão de literatura "consiste em detectar, consultar e obter a bibliografia e outras matérias úteis para propósitos do estudo, dos quais extraímos e sintetizamos informações relevante e necessária para o problema da pesquisa".

Além disso, esse trabalho embasa-se em autores como Machado (2002), Moreira e Candau (2012), e Giddens (2005). E para interliga a metodologia proposta nessa pesquisa, também se fez do uso do materialismo do discurso analítico, critico e reflexivo a luz do pensamento da cultura e educação.

\section{Implicações da cultura e da sociedade na educação}

A cultura é a identidade de um povo que vive em determinada localização, onde seus atores sociais: escola-gestão-aluno-família assumem múltiplos papéis sociais; atribuindo-se responsabilidade, competência, habilidades artísticas, habilidades profissionais e valores culturais. Que muitas vezes, alguns não são aceitos pela sociedade de maneira geral, mas, que assumem papéis correspondentes as normas e costumes construído ao longo da história da humanidade.

Vale ressaltar que, a escola é o principio de valor normativo construído através da cultura intelectual que por meio da educação e suas interlocuções de aprendizagens, construí e reconstroem a própria criação terminológica, epistemológica e dialética da cultura, sociedade e educação.

Assim, dessa forma, podemos enfatizar que o pensamento crítico, reflexivo e analítico é uma ferramenta pedagógica e didática diante do processo de ensinoaprendizagem e suas ações subjacentes; onde se formulou esses fenômenos, e adjacentes os quais proverá de práxis significativas e ressignificativa no campo educacional. Proferindo assim, encontra-se a importância dessas temáticas para educação e para elaboração de práxis pedagógica condizentes com a realidade institucional e contextual de uma região.

Então, vamos tecer esse plano da seguinte forma: as religiões e suas praticas no cenário educacional é tema de discussão entre os alunos, pais, educadores e mestres. Pois, algumas religiões não permitem aos devotos que pratiquem certas 
ações diante de algo ou alguém. Isso porque, certos costumes e tradição como, por exemplo: as Testemunhas de Jeová são maus vistos por que não aceitam em caso de tragédia sangue de outra pessoa. Os evangélicos em grande maioria não usam shorts ou saia, e nem participam de missas.

Diante desse cenário, a gestão escolar e os educadores devem agir com prudência ética a criar projetos de vidas, onde possam ser inseridos pessoas que seguem as mais diversas religiões, de modo a promover a sensibilização, o respeito e tolerância entre os membros. De outra forma, observa-se que as pessoas/crianças com transtorno do Neurodesenvolvimento ou com deficiências múltiplas não são tratadas como deveria ser enquanto ser humano.

Muito embora, as leis implicam nos modos de atuação. Ainda, algumas escolas não respeitam a questão da acessibilidade e nem implantam a sala de recursos multifuncional.

O que a gestão de dever fazer é sua obrigação como tal. Além do mais, agir como respeito e competência técnica e humana para conhecer e saber fazer nos campos interdisciplinares, onde se encontra a educação e, obviamente, o ser-estar em harmonia em função do desenvolvimento integral da aprendizagem e seus múltiplos valores humanos.

Conforme o pensamento de Giddens (2005) esse triple dar-se-á em consonância idiossincráticas mutáveis e não mutáveis ancorados em costumes culturais, valores e atitudes da pessoa, de modo que estes elementos por sua essência estão enraizados numa determinada cultura. Vale ressaltar que outras características intrínsecas como a personalidade, também influência ou até mesmo pode determinar os valores e as normas da pessoa/cultura/sociedade.

Para tanto, é importante destacar que essa tríade: valores-normas-cultura são aspectos propriamente sociais, que atuam em sincronia, de maneira a implica na conduta assertiva ou desadaptativas de uma pessoa inserida no contexto social.

Nessa interação, Giddens (2005, p. 38) aponta que "as normas são regras de comportamentos que refletem ou incorporam os valores de uma cultura". Assim, dessa forma, compreende-se que os valores $e$ as normas são elementos sociais fundamentais no controle de comportamentos ditos fora de "padrão" de uma sociedade (GIDDENS, 2005).

Nesse diálogo, podemos enfatizar, a exemplo, que na nossa cultura não é permitido sair por aí pelado pelas ruas, avenidas e universidade e etc. Isso ocorre porque não é uma norma e nem tampouco uma valor da nossa cultura. Além do mais, isso vai contra as leis, regras, normas e valores da nossa sociedade. Porém, existem também, aqui no nosso país, lugares que permitem a nudez. O exemplo das praias de Tambaba em João Pessoa-PB e Abricó no Estado do Rio de Janeiro-RJ. 
Desta forma, observa-se que a cultura se faz e se constrói aos modos de uma sociedade e vice-versa. Dito isto, a relação entre os valores e normas são construídos e/ ou reconstruídos aos passos da evolução da cultura. A grosso modo, permita-me elencar aqui outro elemento que estar ancorado cognitivamente, que é a aculturação a união de costumes e tradição de uma cultura de povo junta a de outro povo. Essa ação impele de certa forma, a ruptura positiva e negativa versada por mudanças normativas de uma cultura.

\section{1 implicações do etnocentrismo na educação}

O etnocentrismo pode ser compreendido como manifestações ideológicas, comportamentais e sociológica contrária aos costumes, regras, valores, tradição e atitudes de uma cultura, provocando imposições, através de comportamentos, gestos e verbalização contrariamente a de outra cultura ( CANDAU, 2011).

Indo de encontro com essas implicações, podemos destacar que no Brasil existe isso, onde algumas pessoas de uma região são contrárias aos valores, costumes e tradição de outra. O pessoal do Sul e Sudeste tem a impressão que os nordestinos são pessoas inferior por enfrentar o sol quase o ano todo ( CANDAU, 2011).

Ou ainda, tem no seu imaginário que os nordestinos passam por necessidades financeiras, sanitária, infraestrutura e alimentares e entre outros elementos. Quando na verdade em hipótese, isso é um problema nacional, mas, o preconceito existe. Também, existe a questão do gosto musical.

\section{Os processos de socialização e sua conexão com os papéis sociais e educacionais na formação da identidade.}

A socialização é o processo de compartilhamento de informações intelectuais, culturais, locais, comportamentais, brincadeiras, artes, gestos, valores, crenças, cultura, costumes, vivencias e experiências que promovem o processo de interação social. De outra forma, podemos dizer que é dialética social de aprendizagem, onde nós aprendemos por meio da interação social, signos, símbolos, significados construídos pela cultura (GIDDENS, 2005, VIGOTSKY, 2007).

Corroborando com essa perspectiva, Giddens (2005) Adentra nesse diálogo, de modo a considerar que a socialização ocorre desde a concepção da pessoa. Isto é, desde o ato da fecundação, onde o feto adquiri aspectos dos pais, e vai aprendendo com o meio. Assim, nesse manejo de socializar e conectar, a pessoa se faz na cultura como meio de construção da sua identidade (GIDDENS, 2005, VIGOTSKY, 2007).

Ainda conforme, o auto supracitado, observa-se que coexiste duas fases para a socialização ocorrer. Os agentes de socialização são grupos ou contextos sociais em 
que ocorre processo significativos de socialização. A socialização primária ocorre na primeira infância e é o mais intenso período de aprendizado cultural. É o tempo em que as crianças aprendem a língua e os padrões básicos de comportamento que formam a base para o aprendizado (GIDDENS, 2005 p. 42).

Percebe-se que a socialização está ancorada nas relações sociais e suas configurações de construção de laços afetivos e emocionais que se estabelecem na infância com as pessoas de referencias nos vínculos familiares. Ou seja, ocorre o compartilhamento voluntário e involuntário de comportamentos, gestos, linguagem, brincadeira, valores, costumes, crenças e atitudes, os quais a criança, tende-se a introjetar e/ ou projetar no presente futuro, de modo que servirá de base para replicar ou não na segunda fase.

Corroborando com esse seguimento, posterior a essa fase, Giddens (2005. p. 43) enfatiza que "A socialização secundária tem lugar mais tarde na infância e maturidade. Nessa fase, outros agentes de socialização assumem algumas responsabilidades que antes eram da família". Observa-se que nessa concepção, a criança se fazer a construir o seu pensamento baseado nas vivências e experiências do seio familiar que agora será expandido para o social.

Nessa teia da socialização, Giddens (2005. p. 43) compreende que é " através do processo de socialização, os indivíduos aprendem sobre os papeis sociais." Esse mecanismo permite, a saber quem são os profissionais responsáveis pela sua saúde inserido na Unidade Básica de Saúde da sua área, quem é estudante, quem é o pastor, quem é o professor, quem é pedreiro, quem é que estar lendo esse texto. Em fim, são múltiplos papéis que são representados pela socialização que também é a identidade da pessoa enquanto ser social e profissional. Assim, são as representações sociais dos papéis sociais, onde temos que agir como tal dentro da cultura geral e/ ou educacional.

\section{A importância de discutir a questão racial na escola}

A educação brasileira, ainda é preconceituosa aos olhos das práxis de minoria que a exercem. Isto porque, alguns professores carregam na sua ideologia um radical, supostamente de superioridade, mais isso é minoria mesmo em pleno século XXI. Veja outro motivo! As discussões das cotas para ingresso em UNIVERSIDADE é uma tema ambivalente que desperta: ódio, poder, empatia, respeito e desrespeito a dignidade da à pessoa. Nesse caso, existem requisitos que, muitas vezes, são ignorados, ou algumas pessoas ditas de cor preta com poder financeira melhor, usam desse meio para obter resultados melhores. Ainda, em tese, isso implica em desmerecer o potencial intelectual das pessoas pretas (GOMES, 2012) 
Bem isso só foi para ilustrar que essa temática ainda não foi superada, e ainda, falta muito para tal. E segredo está no trabalho voltado para educação infantil. Ou seja, trabalhar na Base, ou ainda, desenvolver ações que descreva a importância das pessoas negras no Brasil e no Mundo, e que todos nós somos iguais perante a Lei, diferentes nos modos d3e ser o que nos tornam semelhantes e iguais (GOMES, 2012).

Diante do exposto e dialogando com "A Questão racial na escola: desafios colocados pela implementação da lei 10.639/03", o autor Gomes (2012) chama atenção que essas implicações postuladas pela lei instituídas em (2003), implicou nos fundamentos direcionados para as atividades escolares. Onde ficou instituído que todas as escolas a partir de então, deve trabalhar a história África e da Cultura AfroBrasileira nos currículos dos estabelecimentos de ensino públicos e privados da educação básica.

Corroborando com Gomes (2012) em nota sobre a temática em site, percebese que essa lei:

\begin{abstract}
A Lei 10.639/03 propõe novas diretrizes curriculares para o estudo da história e cultura afro-brasileira e africana. Por exemplo, os professores devem ressaltar em sala de aula a cultura afro-brasileira como constituinte e formadora da sociedade brasileira, na qual os negros são considerados como sujeitos históricos, valorizando-se, portanto, o pensamento e as ideias de importantes intelectuais negros brasileiros, a cultura (música, culinária, dança) e as religiões de matrizes africanas. fonte: https://educador.brasilescola.uol.com.br/estrategias-ensino/lei-10639-03ensino-historia-cultura-afro-brasileira-africana.htm
\end{abstract}

Nesse contexto, podemos dizer coexiste uma falha nos modos de ensino da educação. Isso porque, nos levem a crer que o ensino ainda e vulnerável a uma ideologia de poder marcada por práxis ainda tradicional. Assim, dessa forma, implica dizer que não houve essa ruptura de paradigmas nesses últimos 17 anos. Tanto é, que essa temática ainda desperta ódio notório em algumas regiões do país, se não dizer no Brasil.

Nessa temática, podemos destacar que o futebol a nível mundial, nos últimos meses, os jogadores vem passando por preconceito por parte de treinadores e de torcedores. Isso ou quase tudo parte do principio da educação e do ensino. Porque não existe saúde, sem educação, nem tampouco educação sem educação.

Percorrendo em resposta para que esses atos não venham ocorrer, ou que sejam reduzidos em curto prazo, é importante destacar que a Lei 10.639/03, enfatiza que:

"Com a Lei 10.639/03 também foi instituído o dia Nacional da Consciência Negra (20 de novembro), em homenagem ao dia da morte do líder quilombola negro Zumbi dos Palmares. O dia da consciência negra é marcado pela luta contra o preconceito racial no Brasil. Sendo assim, como trabalhar com essa temática em sala de aula? Os livros didáticos já estão quase todos adaptados com o conteúdo da Lei 10.639/03, mas, como as ferramentas que os professores podem utilizar em sala de aula são múltiplas, podemos recorrer às iconografias (imagens), como pinturas, fotografias e produções cinematográficas." fonte: https://educador.brasilescola.uol.com.br/estrategiasensino/lei-10639-03-ensino-historia-cultura-afro-brasileira-africana.htm. 
É consenso que a cultura africana contribui para o desenvolvimento de várias nações. Sendo assim, o que poderia explicar o racismo na escola ou em qualquer ambiente. Tendo em vista que a sociedade é a extensão da escola e vice-versa. ? Primeiro cada ser humano é único na sua natureza de personalidade e carrega traços mutáveis e imutáveis, mais, não dar o direito de afrontar o outro com desrespeito.

Porém, existem outras questões culturais e ideológicas que possam estar por traz dessas ações. Mais de modo geral, a educação emerge como note para mudanças de comportamento ideológico pautado no ensino ético, didático e cultural e/ou a aculturação dos modos atuais.

Por outro lado, observa-se que isso é uma questão de valores, de cultural, de identidade e tradições que devem ser enfatizada na sua totalidade baseadas nos princípios éticos e moral do foi, do que é, do que representa a dignidade humana e de empatia genuína. Não existe cultura alguma sem atos radicais, autoritários, fascista, nazista, comunista, socialista e capitalista que de certo modo, levem a traços democráticos mesmo que sejam em pequenos detalhes (direito a vida) a democracia.

Assim dessa forma, compreende-se a construção de uma democracia deve-se a uma sociedade que lutem pelos seus direitos e assuma seus deveres enquanto pessoas inseridas numa sociedade. Dito isto, o racismo estar no campo preconceituoso, logo, assim, está na área afetiva do ser humano em comportamentos estereotipados e na discriminação.

Para que de fato a luta possa aconteça contra o racismo em todas as instancia da vida, é preciso que os professores, a sociedade e os governantes pensem na mesma linha de raciocínio. Ou que em tese, possibilite políticas públicas condizentes com a realidade, de modo a garantir os direitos por leis, à dignidade humana. Acredito que esse é, ou já esteja em prática, mais que prática é essa que não demonstram resultados positivos em média escala?

A relação de uma sociedade com seu povo são baseados naquilo que é construído ou reconstruído ao longo dos tempos. Nesse sentido, a relação entre a construção de uma sociedade mais democrática e a luta antirracista é representação do que é vivo, sentido, onde as pessoas agem conformem o que construído. Seja positivo ou negativo.

\section{A importância da cultura e da sociedade na educação}

A educação é a essência condutora de uma sociedade, pois é a partir dela que as pessoas, grupos, país e as escolas tendem-se a seguir um determinado padrão normativo de ordem, regras, costumes, tradições e progresso instituído na estrutura 
educacional de uma comunidade. No entanto, quando ocorrem rupturas entre os sistemas; econômico, cultural e educacional entre outros se pode, notar que alguns aspectos reguladores desses segmentos, muitas vezes, podem se romper ou atuar como agente rompedor de vínculos entre as pessoas, grupos, ou até mesmo de uma nação.

Assim, dessa forma, podemos notar que nessa conjuntura, foi instaurado "tempos de crise e desconfiança". Isto porquê, de modo geral, percebe-se que na conjuntura atual, a população vem sofrendo abuso excessivo de aumento dos preços, intolerância, racismo, preconceito e entre outros fatores de crise e suas diversificações

de consumo, postura e suas implicações éticas que podem emergir na sala de aula.

Assim, desta forma, compreende-se que esse fenômeno só pode ser mudado; o curto, médio ou longo prazo, através da educação da pessoa, que, posteriormente, implicará na conduta ética e moral, de modo que a pessoa refletirá sobre as suas ações e seus pensamentos em sala de aula, nos ambientes sociais e familiares. E para tal elemento ocorrer, valerá da cultura e da sociedade emancipatória.

Deste modo, compreende-se que para conduzir uma sociedade justa e digna é preciso tecer a educação como ferramenta indispensável para o desenvolvimento integral. Com isso, Lancillote (2010) destaca que a pesquisadora e educadora, Montessori, enfatiza que a individualização, é o mecanismo de uma sociedade organizada, onde existe ou coexiste o dever de extrair conhecimentos das novas tecnologias em face da organização didática que melhor correspondem aos anseios da comunidade que aflora constantes transformações na atualidade (LANCILLOTE, 2010).

Por outro lado, Bollonw, outro estudioso no campo da educação, destaca os princípios da confiança $x$ desconfiança suas implicações diante da educação, na qual quando a confiança não for trabalhada adequadamente nas series inicias, através de princípios e valores humanos de bons atos, atitude e comportamentos adaptativos, pode ocorrer a desconfiança quando a pessoa deixar agir em conformidade a estes princípios propostos pela cultura e da sociedade (RÖHR, 2011).

Diante exposto, compreende-se que a tarefa da educação frente às crises ou desconfiança generalizada sempre existiu, num plano cultural e social, de modo que estes fatores partem de uma visão de mundo, teórica e filosófica. Porém, cabe ao educador direcionar suas práxis afins, de mediar ações frente aos conflitos desta natureza.

De tal modo que, é possível articular ações culturais e sociais como princípios, onde possa provocar momentos de transformações na dialética interativa da díade: professor-aluno. Ou seja, transformar a realidade a partir daquilo que conhecemos 
como algo negativo. $E$ ir além dos aspectos positivos (MARTINS, 2016). Pois, acredita-se que essas práxis são capazes de facilitar a mudanças de uma sociedade, através do construto do qual homem ou professor quer formar? E como o mesmo vai agir? Quais os recursos para quer isso ocorra. Então, a resposta é! É olhar profundamente para as atribuições do professor dentro e fora da sala de aula.

Assim, dessa forma, compreendemos que o campo pedagógico são provocações e as condições às quais a pessoa/ ou aluno tende-se a atuar de forma autônoma, onde sua capacidade reflexiva e critica da realidade o transportará para a criação do seu mundo, de forma responsável e coerente com o mundo, com as pessoas e principalmente consigo mesmo. Assim, dando ênfase a reflexão-açãorealidade diante de si e do outro significante diante de uma cultura e sociedade educada (LANCILLOTE; 201;RÖHR, 2011).

\section{Considerações finais}

Ao considerar a importância da cultura e da sociedade na educação de modo geral, observa-se que precisamos avançar mais ainda nas relações humanas e suas implicações culturais, costumes, tradições, gêneros, questões raciais, regionais, estaduais, nacionais e entre outros movimentos pertencentes aos modos de ser cultural e social da pessoa inserida na escola. Isso significa que as escolas precisam trabalhar ou readequar-se ao multiculturalismo como ferramenta pedagógica e didática nesse campo.

Percebe-se que é a partir dessa perspectiva que os resultados ditos favoráveis nesse meio emergem satisfatoriamente no ambiente escolar. Assim, os achados como: responsabilidade, competência, habilidades artísticas, habilidades profissionais e valores culturais podem estar presentes cada vez mais no cenário educacional.

No entanto, a educação brasileira, ainda é preconceituosa aos olhos das práxis da minoria de alguns professores que a exercem de maneira desagradáveis seus alunos e/ou não estão qualificados para tal função. Igualmente, nota-se que algumas escolas não respeitam a questão da acessibilidade e nem implantam a sala de recursos multifuncional. $E$ isso também é questão cultural e social de uma educação digna para todos.

É por essas razões que o presente estudo torna-se relevante ao considerar esses aspectos de suma importância na educação integral. Pois, uma sociedade proativa não será valorizadas se não elencar sua essência cultuara e social dentro de suas interfaces multifatoriais que são encontradas na dinâmica escolar, pedagógica e didática trabalhada na educação.

E por fim, espera-se que o trabalho possam impelir outros estucadores e/ou estudiosos do comportamento a considerar a efetivação interacionista da cultura e da 
sociedade no processo de socialização, interação, compartilhamento de informação, conhecimento e sabedoria no âmbito escolar. Assim, aprendizagem será algo natural e prazeroso para as pessoas.

\section{Referências}

GIDDENS, Anthony. Sociologia.4 ed. São Paulo: Artmed, 2005.

https://educador.brasilescola.uol.com.br/estrategias-ensino/lei-10639-03-ensinohistoria-cultura-afro-brasileira-africana.htm.

LANCILLOTTI, Samira Saad Pulchério. PEDAGOGIA MONTESSORIANA: ensaio de individualização do ensino. Revista HISTEDBR On-Line, 2010, 10.37e: 164-173. MARTINS, Ligia Márcia. Fundamentos da Psicologia Histórico-Cultural e da Pedagogia Histórico-Crítica. Currículo Comum para o Ensino Fundamental Municipal. Bauru:

Prefeitura Municipal de Bauru, p. 41-79, 2016.

MOREIRA, Antônio Flávio. Multiculturalismo: diferenças culturais e práticas pedagógicas. Editora Vozes Limitada, 2012.

Röhr, Ferdinand, Confiança - um conceito básico da Educação no pensamento filosófico e pedagógico de Otto Friedrich Bollnow. EccoS Revista Científica [en linea] 2011, (Julio-Diciembre) : [Fecha de consulta: 3 de junio de 2018] Disponible en:<http://www.redalyc.org/articulo.oa?id=71522347012> ISSN 1517-1949 SAMPIERI, Roberto. Hornandez; COLLADO, Carlos. Fernandez; LUCIO, Pilar. Baptista. (2013). Metodologia de pesquisa. 5. ed. - Porto Alegre: Penso, p.76. VIGOTSKY, L. S. A Formação Social da Mente: o desenvolvimento dos processos psicológicos superiores. Organizadores Michael Cole et al.(J. Cipolla Neto, SM Barreto, C. Afeche, trads.). 2007. 